\title{
Teaching Video NeuroImages: Convergence retraction nystagmus due to compressive lesion of the dorsal midbrain
}

Edward Margolin, MD, and Seema Emami, MD

Neurology ${ }^{\circledR}$ 2020;94:e2285-e2286. doi:10.1212/WNL.0000000000009481

Figure Sagittal T1 postcontrast MRI demonstrates large mass compressing dorsal midbrain

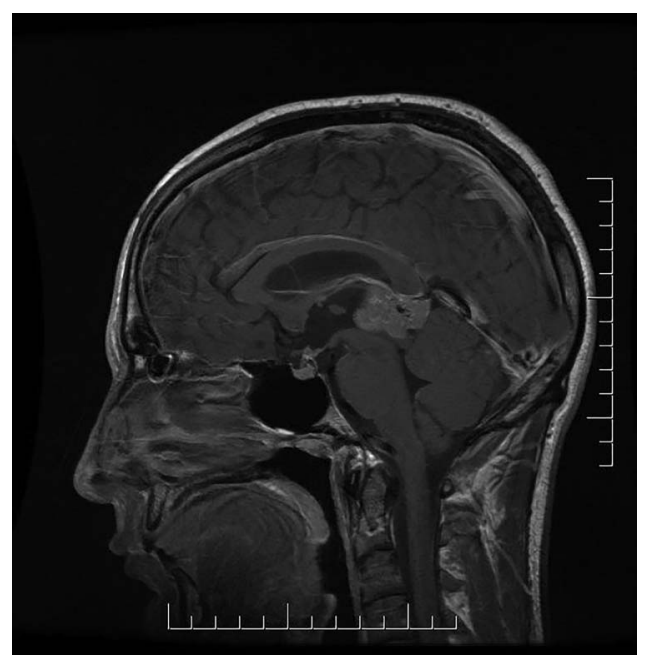

A 28-year-old man had experienced binocular diplopia for the last 2 months. Around the same time, he noticed mostly nocturnal polyuria and polydipsia and eventually was diagnosed with diabetes insipidus. Extraocular motility testing demonstrated jerky convergence movements on an attempted upgaze and mild lid retraction (video). Urgent MRI of the brain revealed a large mass in the dorsal midbrain region, which was also compressing the hypothalamus (figure). The lesion was biopsied and a diagnosis of primary intracranial germinoma arising from pineal tissue was made. Treatment with lowdose radiotherapy commenced. Characteristic clinical features of convergence retraction nystagmus in this case allowed rapid localization of the lesion, its diagnosis, and eventually treatment. ${ }^{1}$

\section{Study funding}

No targeted funding reported.

\section{Disclosure}

The authors report no relevant disclosures. Go to Neurology.org/N for full disclosures.

\author{
Correspondence \\ Dr. Margolin \\ Edward.margolin@ \\ sinaihealthsystem.ca
}

\section{MORE ONLINE}

\section{- Video}

$\rightarrow$ Teaching slides

links.lww.com/WNL/

B88 
Appendix Authors

\begin{tabular}{lll}
\hline Name & Location & Contribution \\
\hline $\begin{array}{l}\text { Edward } \\
\text { Margolin, } \\
\text { MD }\end{array}$ & $\begin{array}{l}\text { University of Toronto, } \\
\text { Department of } \\
\text { Ophthalmology and Vision } \\
\text { Sciences, Canada }\end{array}$ & $\begin{array}{l}\text { Writing up manuscript, } \\
\text { proofing final manuscript, } \\
\text { data collection }\end{array}$ \\
\hline $\begin{array}{l}\text { Seema } \\
\text { Mmami, }\end{array}$ & $\begin{array}{l}\text { University of Toronto, } \\
\text { Department of } \\
\text { Ophthalmology and Vision } \\
\text { Sciences, Canada }\end{array}$ & $\begin{array}{l}\text { Writing up manuscript, } \\
\text { proofing final manuscript, } \\
\text { data collection }\end{array}$ \\
\hline
\end{tabular}

\section{Reference}

1. Shields M, Sinkar S, Chan W, Crompton J. Parinaud syndrome: a 25-year (19912016) review of 40 consecutive adult cases. Acta Ophthalmol 2017;95:e792-e793. 


\section{Neurology}

Teaching Video NeuroImages: Convergence retraction nystagmus due to compressive lesion of the dorsal midbrain

Edward Margolin and Seema Emami

Neurology 2020;94;e2285-e2286 Published Online before print May 4, 2020

DOI 10.1212/WNL.0000000000009481

This information is current as of May 4, 2020

\section{Updated Information \&} Services

References

Subspecialty Collections

Permissions \& Licensing

Reprints including high resolution figures, can be found at: http://n.neurology.org/content/94/21/e2285.full

This article cites 1 articles, 0 of which you can access for free at: http://n.neurology.org/content/94/21/e2285.full\#ref-list-1

This article, along with others on similar topics, appears in the following collection(s):

Clinical neurology examination

http://n.neurology.org/cgi/collection/clinical_neurology_examination MRI

http://n.neurology.org/cgi/collection/mri

Neuroendocrinology

http://n.neurology.org/cgi/collection/neuroendocrinology

Ocular motility

http://n.neurology.org/cgi/collection/ocular_motility

Information about reproducing this article in parts (figures,tables) or in its entirety can be found online at:

http://www.neurology.org/about/about_the_journal\#permissions

Information about ordering reprints can be found online:

http://n.neurology.org/subscribers/advertise

Neurology ${ }^{\circledR}$ is the official journal of the American Academy of Neurology. Published continuously since 1951 , it is now a weekly with 48 issues per year. Copyright (C) 2020 American Academy of Neurology. All rights reserved. Print ISSN: 0028-3878. Online ISSN: 1526-632X.

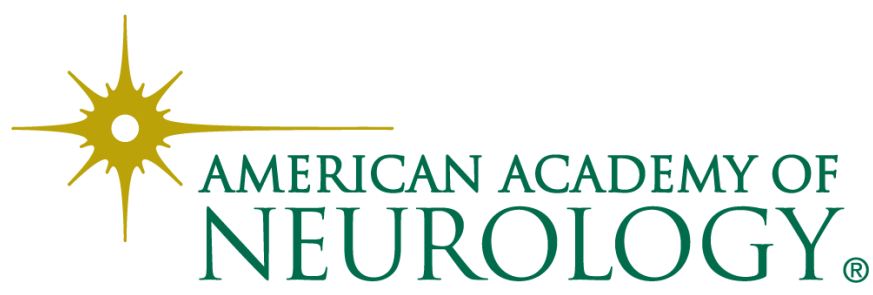

